\title{
Sorcin is involved during embryo implantation via activating VEGF/PI3K/Akt pathway in mice
}

\author{
Kanchan Gupta, Vijay Kumar Sirohi, Suparna Kumari, Vinay Shukla, Murli Manohar, Pooja Popli and Anila Dwivedi \\ Division of Endocrinology, CSIR-Central Drug Research Institute, Lucknow, Uttar Pradesh, India \\ Correspondence should be addressed to A Dwivedi: anila.dwivedi@rediffmail.com
}

\begin{abstract}
Our earlier studies have demonstrated the cyclic variation and also the altered expression of sorcin in endometrium during early-to-mid-secretory phase transition in women with unexplained infertility. The current study was undertaken to establish the functional role of sorcin in endometrial receptivity in mice. Results indicated that sorcin was highly expressed during the window of implantation in mice and functional blockage of sorcin caused significant reduction in number of implanted blastocyst. The receptivity markers (i.e.Integrin $\beta 3$, HBEGF, IGFBP1, WNT4 and Cyclin E)) were found to be downregulated in sorcin knocked down uterine horn on day 5 as compared to untreated horn. The reduced attachment and expansion of BeWo spheroids on RL95-2 endometrial cells with sorcin knock down, in in vitro model of endometrium-trophoblast interaction further supported these findings. Uterine sorcin expression pattern during estrous cycle and in delayed implantation mice model suggested the upregulation of sorcin by estrogen. The functional blockade of sorcin induced the intracellular $\mathrm{Ca}^{+2}$ levels in endometrial epithelial cells (EECs), which indicated that altered $\mathrm{Ca}^{+2}$ homeostasis might be responsible for implantation failure. Sorcin silencing led to significant reduction in the expression of angiogenic factor VEGF and its downstream effector molecules i.e. PI3K, Akt and NOS. The migratory and invasive properties of HUVECs were abrogated by anti-VEGF or by adding culture media from sorcin blocked EECs, which indicated that sorcin might mediate angiogenesis during implantation. Taken together, sorcin is involved in the regulation of $\mathrm{Ca}^{+2}$-mediated angiogenesis via VEGF/PI3K/Akt pathway in endometrial cells and plays a crucial role in preparing the endometrium for implantation.
\end{abstract}

Key Words
- sorcin
- embryo implantation
- VEGF
- angiogenesis

Journal of Molecular Endocrinology (2018) 60, 119-132

\section{Introduction}

Embryo implantation involves a complex sequence of signaling events that are crucial for the establishment of pregnancy (Cha et al. 2012). A large number of identified molecular mediators have been postulated to be involved in early feto-maternal interaction (Kodaman \& Taylor 2004, Yoshinaga 2008). These mediators include molecules associated with uterine receptivity e.g. cytokines, growth factors, adhesion molecules and extracellular matrix components, which play a crucial role in preparation and development of an appropriate endometrium for blastocyst adhesion and implantation (Lessey et al. 1992, Singh et al. 2010). In rodents, the implantation process initiates with an increased uterine vascular permeability at the sites of blastocyst apposition where VEGF plays significant role (Demir et al. 2010, Zhang et al. 2013). The cyclic changes in vascular endothelial growth factor 
(VEGF) and its receptors have also been reported in the human endometrium (Sugino et al. 2002, Hannan et al. 2011) as well as in rat and mouse uterus (Herve et al. 2006, Walter et al. 2010).

Calcium-binding proteins such as CaBP-9k and CaBP$28 \mathrm{k}$ have been reported to be involved in the regulation of calcium availability in the uterine environment for successful implantation (Nie et al. 2000, Luu et al. 2004). S100A11, a member of the $\mathrm{S} 100$ protein family containing two EF-hand calcium-binding motifs, is also reported to be a crucial mediator in embryo adhesion, endometrial receptivity and immune tolerance by regulating calcium uptake and its release from intracellular $\mathrm{Ca}^{+2}$ stores (Liu et al. 2012). Knockdown of endometrial S100A11 causes reproductive failure by attenuating embryo implantation in mouse (Liu et al. 2012). Although the detailed mechanism and functions regulated via calciumbinding proteins in uterus are not clear as yet, these appear to play a significant role in the process of implantation.

Sorcin (soluble resistance-related calcium-binding protein) is a cytoplasmic protein that is tightly associated with free ribosomes, rough endoplasmic reticulum cisternae, mitochondria, nuclear membrane and microtubules (Lalioti et al. 2014). Sorcin is a part of the Penta-EF-hand (PEF) protein family, with typical calciumbinding sites located in the first pair of EF-hands and have molecular mass of $22 \mathrm{kDa}$ (Van der Bliek et al. 1986, Xie et al. 2001). Sorcin is expressed in a wide set of human cell types such as cardiac cells, vascular smooth muscle cells and adrenal medulla and participates in the regulation of a variety of cell-specific calcium-dependent functions (Matsumoto et al. 2005, Colotti et al. 2014). However, not much information is available on the role of sorcin in female reproductive functions. The upregulated expression of sorcin during secretory phase as compared to proliferative phase has been reported in the endometrium of fertile women (Chen et al. 2009). Our earlier study in women with unexplained infertility, suggested the plausible role of sorcin during 'early-secretory (pre-receptive) to midsecretory (receptive) phase transition' in the endometrium (Manohar et al. 2014). Based on this, we hypothesized that sorcin might play a significant role in preparing the endometrium for blastocyst implantation. In the present study, we have established the functional role of sorcin in uterine receptivity and embryo implantation in mice model. In addition, hormonal regulation and molecular mechanism of action of sorcin in mediating angiogenesis in endometrial cells during the peri-implantation period were explored.

\section{Materials and methods}

\section{Animals and tissue preparation}

Adult Balb/c mice aged 8-10 weeks were used in the study, and all experiments were performed according to the standards specified by the Institutional Animal Ethics Committee of Central Drug Research Institute, Lucknow. The estrous cycle was staged by examining the vaginal smears as previously described (Byers et al. 2012). The mice were killed by cervical dislocation followed by immediate collection of uterine horns from adult females at the diestrus, proestrus, estrous and metestrus stages ( $n=3$, per stage). Uterine horns were dissected out and immediately stored in $-80^{\circ} \mathrm{C}$.

Adult female mice were bred with fertile males (female to male: 3 to 1 ) overnight (12h), and the vaginal plug was checked the following morning. The day of finding vaginal plug was considered as day 1 of pregnancy (D1). Pregnant mice were divided into 5 groups (D1, D4, D5, D6 and D7) with 3 mice in each group. The implantation sites on D5 of pregnancy were identified by intravenous injection of $0.1 \mathrm{~mL}$ of $1 \%$ Evans Blue (Sigma). Mice in each group were killed, and uterine horns were immediately dissected out and flushed with saline and immediately stored in $-80^{\circ} \mathrm{C}$.

Steroid hormonal treatments were initiated 2 weeks after ovariectomy as previously described (Liang et al. 2010). All steroids were dissolved in olive oil. The ovariectomized mice were treated with a subcutaneous injection of estradiol ( $100 \mathrm{ng} / 30 \mathrm{~g}$ body weight), progesterone ( $1 \mathrm{mg} / 30 \mathrm{~g}$ body weight) or a combination of the same doses of estradiol and progesterone, whereas mice of control group received the vehicle only. After $24 \mathrm{~h}$ of hormonal treatment, uterine samples were collected.

\section{Delayed implantation model}

Delayed implantation was induced in mice as previously described protocol (Liang et al. 2010). Pregnant mice were ovariectomized under anaesthesia on D3 of pregnancy. Delayed implantation was maintained from D4 to D7 by injecting progesterone ( $1 \mathrm{mg} / 30 \mathrm{~g}$ body weight). Estrogen ( $25 \mathrm{ng} / 30 \mathrm{~g}$ body weight) was given to progesterone-primed delayed implantation mice to initiate implantation. The mice were killed, and uteri were collected $24 \mathrm{~h}$ after hormonal treatment. Delayed implantation was confirmed by flushing the blastocysts from -uterine horn. The implantation sites after activation were identified by intravenous injection of Evans Blue dye (1\%). 


\section{Bioneutralization of sorcin}

Pregnant female mice underwent mini laparotomy under anesthesia on D4 of the window of implantation to deliver the $1.5 \mu \mathrm{g}$ of sorcin antibody (sc-100859; Santa Cruz Biotechnology) in one of the uterine horn, while the other horn (control) received normal mouse IgG, as described previously (Huang et al. 2012). On D5 and D10 of pregnancy, animals were killed and their uteri were photographed to record the number of implanted embryos.

\section{In vivo sorcin knock down}

Pregnant female mice underwent mini laparotomy under anesthesia on D3 of pregnancy to deliver $50 \mathrm{nM}$ of sorcin siRNA (sc-41017; Santa Cruz Biotechnology) in a final volume of $25 \mu \mathrm{L}$ with Lipofectamine RNAiMAX reagent (Thermo Fisher Scientific) per manufacturer's instructions in one of the uterine horn. The other horn (control) received scrambled siRNA, as described (Zhang et al. 2012, Guo et al. 2014, Long et al. 2015). On D5 and D10 of pregnancy, animals were killed and their uteri were photographed to observe the number of implanted embryos. Uterine horns of D5 of pregnancy were dissected out and flushed with saline and stored in $-80^{\circ} \mathrm{C}$ till further processing.

\section{Immunohistochemistry}

Immunohistochemical analysis was performed with minor modifications as described previously (Manohar et al. 2014) using ImmunoCruz ABC staining system (Santa Cruz Biotechnology). Briefly, formalin-fixed and paraffinembedded uterine sections $(5 \mu \mathrm{m})$ were de-paraffinized and rehydrated. The sections were incubated with $0.5 \%$ $\mathrm{H}_{2} \mathrm{O}_{2}$ in PBS for $5 \mathrm{~min}$ to block endogenous peroxidase activity and blocked with 5\% bovine serum albumin along with normal goat serum for $2 \mathrm{~h}$. The sections were then incubated with primary antibody anti-sorcin (sc-100859) in 1:300 dilutions for overnight at $4^{\circ} \mathrm{C}$. For the negative control, IgG was added to the sections and kept for overnight at $4^{\circ} \mathrm{C}$. Further, sections were incubated in biotinylated secondary antibody (1:500; ImmunoCruz $\mathrm{ABC}$ staining system) for $30 \mathrm{~min}$ followed by $\mathrm{ABC}$ enzyme reagent incubation. Staining was achieved with peroxidase substrate $\mathrm{DAB}$ for $5 \mathrm{~min}$, counterstained by hematoxylin for 30s and mounted with DPX (Sigma-Aldrich). Images were captured under light microscope (ECLIPSE TE2000-S, Nikon) at $400 \times$ magnifications. The staining intensity of all these proteins in glandular epithelium, luminal epithelium and stromal compartment were quantified by image analysis software Image-Pro Plus 4.0 (Maryland, USA), and results were expressed as \% image analysis score.

\section{Primary endometrial epithelial cell culture}

Uteri were taken out from adult female mice and tissue was collected in DMEM (Sigma-Aldrich), minced into $1 \mathrm{~mm}$ pieces and incubated with collagenase $(1 \mathrm{mg} / 1 \mathrm{~mL})$ and DNase $(2 \mathrm{ng} / \mathrm{mL})$ in DMEM for $2 \mathrm{~h}$ at $37^{\circ} \mathrm{C}$ with regular mixing. Digested tissue was mechanically dissociated through a $1 \mathrm{~mL}$ tip and resuspended in $2 \mathrm{~mL}$ of fresh DMEM. Supernatant was collected and centrifuged for $2 \mathrm{~min}$ at $600 \mathrm{~g}$ and then the pellet was dissolved in DMEM. Cells were allowed to pass through a $40 \mu \mathrm{m}$ cell strainer placed on top of an open $50 \mathrm{~mL}$ falcon tube. Epithelial cells retained in the strainer were collected in DMEM and then transferred to tissue culture flasks $\left(75 \mathrm{~cm}^{2}\right.$, Corning). Epithelial cells were incubated at $37^{\circ} \mathrm{C}$ with saturating humidity and $5 \% \mathrm{CO}_{2}$.

\section{Trophoblast spheroid adhesion assay}

In order to study the effect of sorcin silencing on embryo implantation, we have quantified attachment of BeWo (human trophoblast cells, obtained from cell repository of National Centre for Cell Science, Pune, India) spheroids to the RL95-2 (human uterine EECs purchased from American Type Culture Collection (Manassas, VA, USA)) monolayer as previously described (Ho et al. 2012). RL95-2 cells were seeded into 96-well plates $\left(5 \times 10^{3}\right.$ cells per well), and cultured for $24 \mathrm{~h}$ to form a monolayer. Cells were washed and transfected according to manufacturer's protocol. Briefly, $20 \mathrm{nM}$ of sorcin siRNA was diluted in $50 \mu \mathrm{L}$ of culture media and added with $50 \mu \mathrm{L}$ of diluted Lipofectamine RNAiMAX Reagent (Invitrogen). The mixture was allowed to incubate at room temperature for $30 \mathrm{~min}$ then given to RL95-2 monolayer for $6 \mathrm{~h}$ followed by incubation of $24 \mathrm{~h}$. Trophoblast spheroids were generated by agitation of BeWo cells on an orbittal shaker at $110 \mathrm{rpm}$ for $16 \mathrm{~h}$. Spheroids $(n=30)$ were delivered to each well over a confluent monolayer of RL95-2 cells in triplicate and incubated for $1 \mathrm{~h}$ at $37^{\circ} \mathrm{C}$ in a humidified atmosphere with $5 \% \mathrm{CO}_{2}$. After $1 \mathrm{~h}$, non-adherent spheroids were removed by centrifugation (with the cell spheroid surface facing down) at $12 \boldsymbol{g}$ for $5 \mathrm{~min}$. Adhered spheroids were counted under a microscope and percent adhesion was calculated by the formula: Ratio of number of adhered spheroids/ number of total spheroids delivered, multiplied by 100. 


\section{Trophoblast spheroid expansion assay}

RL95-2 cells were seeded into 96-well plates $\left(3 \times 10^{5}\right.$ cells per well) and cultured for $24 \mathrm{~h}$ to form monolayer. Then, trophoblast spheroids were transferred to the monolayer (3-5 spheroids/well). To delineate the margins of trophoblast spheroids after co-culture, the spheroids were stained with $10 \mu \mathrm{M}$ of CellTracker Green CMFDA (Invitrogen) for $30 \mathrm{~min}$ before adding to monolayer. Spheroids were photographed after $1 \mathrm{~h}$ and $24 \mathrm{~h}$ co-culture. The length (L) and width (W) of spheroids were measured. The size of spheroids was calculated by the formula: $(\mathrm{L}+\mathrm{W}) / 2$. The expansion of spheroids was determined on the basis of the spheroid size at $1 \mathrm{~h}$ after co-culture. Images were captured using fluorescent microscope (Nikon Eclipse 80i, Nikon) to detect fluorescence.

\section{Western blot analysis}

Mouse uterine tissue samples/EECs were lysed in RIPA buffer (Sigma) supplemented with protease inhibitor cocktail (Sigma) and $1 \mathrm{mM}$ PMSF and incubated overnight in $-20^{\circ} \mathrm{C}$. Supernatant was collected by centrifugation at $20,000 \mathrm{~g}$ for $15 \mathrm{~min}$ at $4^{\circ} \mathrm{C}$. The protein concentration was determined by Bradford method (Manohar et al. 2014). Equal amounts of protein $(20 \mu \mathrm{g})$ were separated by gel electrophoresis and then transferred to ImmunoBlotTM PVDF membrane (Millipore). The membrane was blocked with 5\% skimmed milk and then incubated with appropriate primary antibody (anti-sorcin: sc-100859; anti-VEGF: sc-7269; anti-PI3K: sc-1637; anti-p-PI3K: sc-293115; anti-Akt: \#9272; anti-p-Akt: \#9271; antiVEGFR-2: sab4501645 and anti-NOS: sc-654) at 1:1000 dilution in $0.5 \%$ BSA in Tris buffered saline (TBS) and kept overnight at $4^{\circ} \mathrm{C}$. The membrane was then washed twice with TBST for $5 \mathrm{~min}$ and incubated with a secondary peroxidase-conjugated antibody (1:3000) for $1 \mathrm{~h}$. Antibody binding was detected using enhanced chemiluminescence detection system (GE Healthcare). After developing, the membrane was stripped and re-probed using another primary antibody of interest or $\beta$-actin (sc-1616; Santa Cruz Biotechnology) to confirm equal loading. Each experiment was repeated three times. Quantitation of band intensity was performed by densitometry using Quantity One software (v.4.5.1) and a Gel Doc imaging system (Bio-Rad).

\section{Immunofluorescence imaging}

Mouse primary EECs were grown on coverslips in 12 -well plate and treated with $\mathrm{E}_{2}(10 \mathrm{nM}), \mathrm{P}_{4}(1 \mu \mathrm{M})$ or combination of $\mathrm{E}_{2}(10 \mathrm{nM})+\mathrm{P}_{4}(1 \mu \mathrm{M})$ in primary EECs for $24 \mathrm{~h}$ to determine the expression level of sorcin.

In addition, the expression of sorcin and VEGF receptor-2 (VEGFR-2) was demonstrated in sorcin siRNA or scrambled siRNA-transfected primary EECs from mouse. Cells were fixed in paraformaldehyde (4\%) for $20 \mathrm{~min}$ and permeabilized with $0.1 \%$ Triton X-100 followed by washing with PBS and blocked with 2\% BSA. Next, cells were incubated with anti-sorcin (1:300) antibody for overnight followed by 1-h incubation with fluorescencetagged secondary anti-mouse antibody (1:500), and then mounted on slides with SlowFade Gold Antifade reagent with DAPI (Molecular Probes, Life Technologies). Images were captured at $400 \times$ using Nikon microscope (Nikon Eclipse 80i, Nikon) to detect fluorescence and DAPI emissions.

\section{Flow cytometric analysis}

Primary EECs were seeded $\left(2 \times 10^{5}\right.$ cells/well) into 6-well plate and maintained overnight in phenol red-free media containing $10 \%$ stripped FBS. Next day, cells were transfected with sorcin siRNA for $6 \mathrm{~h}$ in serum-free media according to manufacturer's protocol. Cells were washed with PBS and incubated in serum-free DMEM medium for $24 \mathrm{~h}$. After $24 \mathrm{~h}$, cells were collected by trypsinization and resuspended in PBS. Fluo-3-AM dye $(2 \mu \mathrm{M})$ was added in each sample for $30 \mathrm{~min}$ at $37^{\circ} \mathrm{C}$ in the dark with continuous shaking. Cytosolic free $\mathrm{Ca}^{+2}$ measurement was detected using a FACScan flow cytometer (BD Biosciences, San Jose, CA,USA) with excitation and emission settings at $506 \mathrm{~nm}$ and $526 \mathrm{~nm}$, respectively (Zhang et al. 2004). These experiments were performed three times.

\section{Enzyme-linked immunosorbent assay}

Primary EECs were seeded in 6-well plates $\left(2 \times 10^{5}\right.$ cells/ well) and grown to confluence. Transfection of sorcin siRNA was given for $6 \mathrm{~h}$, and then cells were washed with PBS. Cells were washed with PBS and incubated in serumfree DMEM medium for $24 \mathrm{~h}$. The culture supernatant was collected to measure VEGF concentration using an ELISA kit as specified by the manufacturer (Abcam).

\section{Cell proliferation assay in HUVECs}

MTT assay was used to determine cell viability. Human umbilical vascular endothelial cells (HUVECs, purchased from Life Technologies) were seeded in 96-well plate at a density of $3 \times 10^{3}$ cells/well and allowed to adhere for 
24h. Conditioned media obtained from endometrial cell culture (control and sorcin siRNA transfected) were added $(20 \% \mathrm{~V} / \mathrm{V})$ to these cells for $48 \mathrm{~h}$. In additional group, a blocking anti-VEGF-A antibody was added in the conditioned media from scrambled siRNA-treated EECs. (Print et al. 2004). At the end of incubation, $100 \mu \mathrm{L}$ of MTT $(0.5 \mathrm{mg} / \mathrm{mL})$ was added to the cells and incubated for $2 \mathrm{~h}$ at $37^{\circ} \mathrm{C}$. Following incubation, the supernatant was removed, and $100 \mu \mathrm{L}$ of dimethyl sulfoxide (DMSO) was added. The formazan crystals formed inside the viable cells were solubilized in DMSO, and the optical density was read with Microquant (Bio Tek) at 540 nm.

\section{Wound healing assay}

HUVECs were seeded in 6-well plate and allowed to attain 90-100\% confluency. Conditioned media obtained from scram control or sorcin siRNA-transfected EECs (20\% v/v) added to HUVECs, for $24 \mathrm{~h}$. A vertical scratch was made in the middle of well using a $10 \mu \mathrm{L}$ tip and washed with PBS. Images were captured at $24 \mathrm{~h}$ after supernatant addition. Migration rate was measured by calculating the percent wound closure using the following formula:

$\%$ wound closure $=$ wound at $0 \mathrm{~h}-$ wound at

Th/wound at $0 \mathrm{~h} \times 100$; where $\mathrm{T}$ denotes 'time'

\section{Cell migration/invasion assay}

Cell migration assay was conducted in a 24-well format using cell culture inserts (BD Biosciences) with or without matrigel having a membrane pore size of $8.0 \mu \mathrm{m}$ (Sirohi et al. 2017). Briefly, $2 \times 10^{5}$ HUVECs were seeded into the top chamber. Conditioned media $(20 \% \mathrm{v} / \mathrm{v})$ collected from different groups of EECs were added into the top chamber for $48 \mathrm{~h}$. At the end of the incubation, non-migrated cells present on the upper surface of the membrane were gently removed with a cotton swab. Next, cells on the lower surface of the membrane were fixed in chilled methanol and stained with $0.1 \%$ crystal violet. The cells migrated towards the lower surface of membrane were detected, photographed and counted under an inverted microscope (Nikon ECLIPSE TE2000-S).

\section{Statistical analysis}

All values were presented as the mean \pm s.E.M., as determined from at least three independent experiments. Statistical significance was assessed by one-way ANOVA and Newmann-Keul's test or Student's $t$-test. $P<0.05$ was considered statistically significant.

\section{Results}

Sorcin is upregulated during peri-implantation period and estrous phase

In order to check the differential expression of sorcin during early pregnancy, uterine samples were collected from non-pregnant (NP) mice and from pregnant mice on different days of pregnancy (D1, D4, D5, D6 and D7) and Western blotting was performed. Results indicated that sorcin expression was increased on D4 and D5 i.e. window of implantation and the level was maintained till D6 as compared to NP group $(P<0.001)$. On D7, the expression of sorcin was gradually decreased as compared to D5 $(P<0.001)$ (Fig. 1A). The expression of sorcin was higher at implantation sites but remained low at IIS as observed on D5, D6 and D7; the levels at IIS were comparable to NP uterine tissue (Fig. 1A). Significantly increased expression of sorcin on D4 and D5 revealed its possible role during embryo implantation and endometrial receptivity.

Study on estrous cycle showed that the expression of sorcin was significantly high $(P<0.001)$, during the estrus and metestrus phases as compared to that in proestrus phase (Fig. 1B).

\section{Immunohistochemical localization of sorcin}

To check the cell-specific expression and function of sorcin, immunohistochemistry was performed in uterine tissue. Sorcin expression was increased in the luminal epithelium (LE), glandular epithelium (GE) and also in the stromal cells (S) on D4 of pregnancy (Fig. 2) as compared to that in NP group. As analyzed on D5, in implantation sites, the expression of sorcin was significantly high $(P<0.001)$ in LE ( 6-fold), followed by GE ( 5.4-fold) and in stroma ( $\sim$-fold). The increased expression of sorcin in these cells was continued till D6, whereas on D7, expression of sorcin was detected to be high in stroma $(P<0.001)$ but was less in GE and LE (Fig. 2). Thus, sorcin may be involved in decidualization process as still high levels were detected in stroma during post-implantation.

\section{Inhibition of sorcin caused suppression of uterine receptivity and failure of embryo implantation in mice}

Further, to see whether sorcin is critical for embryo implantation, intrauterine blocking experiments were performed by sorcin-antibody or siRNA injection. Administration of anti-sorcin antibody at D4 p.c. in the uterine horn lumen reduced the number of implants 
A
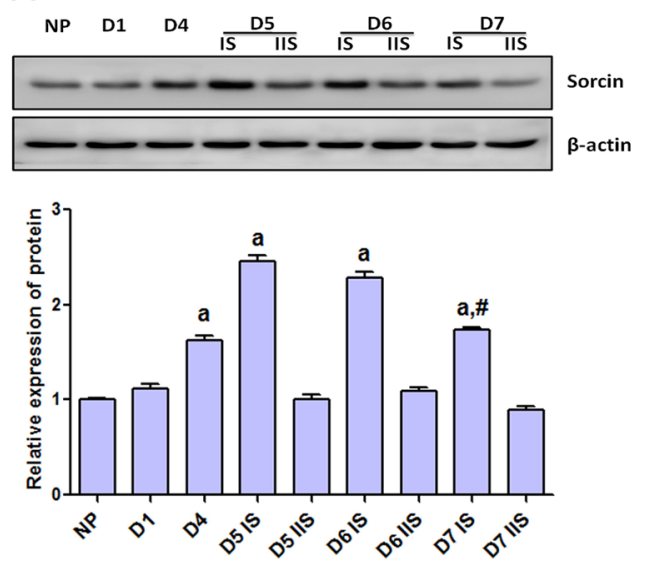
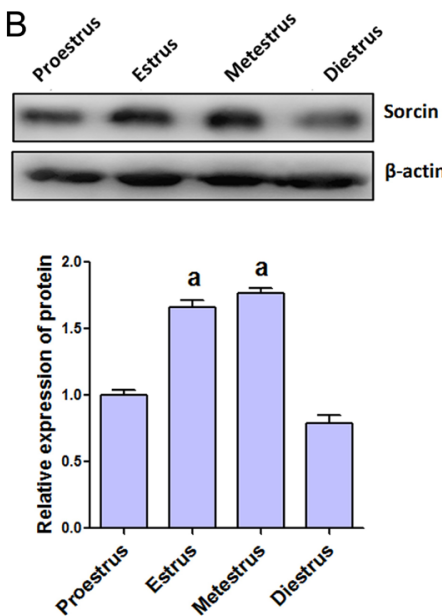

Figure 1

Expression of sorcin during the period of early pregnancy (A) and during estrous cycle (B) in mouse uterus. Protein expression was measured in uterine tissue lysates by Western blotting. Images of representative blots (upper panel) and densitometric quantitation of band intensity (lower panel) have been shown. $n=3$. Results are expressed as mean \pm S.E.M., $P$ values are $P<0.001$ vs non-pregnant, $\# P<0.001$ vs D5 IS and a $P<0.001$ vs Proestrus. IS, implantation site; IIS, interimplantation site; NP, non-pregnant. A full color version of this figure is available at https://doi. org/10.1530/JME-17-0153. effectively ( 5-fold) as observed on D5 and D10, whereas uterine horn treated with control IgG showed normal number of implantations (Fig. 3A). Similarly, the number of implantation sites was significantly reduced ( 6-fold) after the intrauterine injection of sorcin-specific siRNA given on D3 of pregnancy, as compared to that in scrambled siRNA-treated group (Fig. 3B).

The expression of protein level of receptivity markers like Integrin $\beta 3$, IGFBP1, WNT4, Cyclin E and HBEGF was significantly downregulated $(P<0.001)$ in siRNA-injected horn as compared to that in scrambled siRNA (control) group (Fig. 3C) as analyzed on D5. Significant reduction in receptivity markers suggested that sorcin inhibition suppressed the endometrial receptivity and thus reduced the implants number in pregnant mice.

Embryos recovered from the sorcin knocked down horn were morphologically dissimilar as compared over embryos collected from scrambled siRNA-transfected uterine horn (Supplementary Fig. 1, see section on supplementary data given at the end of this article).

We also checked whether control IgG has any adverse effect on implantations. No significant change was observed in control IgG-treated horn as compared to untreated horn (Supplementary Fig. 3).

\section{Sorcin silencing decreased the attachment and expansion of trophoblast spheroids on EECs monolayer}

To analyze whether sorcin is essential for attachment of blastocyst to the endometrial cells, the in vitro attachment assay was performed using endometrial epithelial RL95-2 cells monolayer and BeWo trophoblast spheroids. Transfection efficiency of sorcin siRNA in RL95-2 was confirmed by Western blot analysis. It showed 2.5-fold reduction in sorcin expression after $24 \mathrm{~h}$ of knock down (Supplementary Fig. 2A). Transfection of sorcin siRNA to RL95-2 cells significantly decreased the percent attachment of BeWo spheroids to RL95-2 i.e. EEC monolayer. More than 70\% of the spheroids were attached after $1 \mathrm{~h}$ of co-culture in control and scrambled groups but in sorcin siRNA-transfected group attachment was decreased up to $30 \%(P<0.001)$ (Fig. $4 \mathrm{~A})$. We next investigated whether the expansion of trophoblast spheroids on an EEC monolayer could be reduced by the treatment of EECs with sorcin siRNA. Fluorescent, phasecontrast and merged microscopic images have shown that spheroids attached to EEC monolayer in co-culture, began to flatten and spread on the EEC monolayer at $24 \mathrm{~h}$ (Fig. 4B). However, the decreased expansion ( 3-fold) of trophoblast spheroids on the monolayer was observed on EECs treated with sorcin siRNA. Sorcin siRNA treatment caused reduction $(P<0.001)$ in expansion as compared to that observed in scrambled siRNA control group. These in vitro results showed that sorcin is involved in endometrial receptivity and facilitates attachment and expansion of trophoblast on EECs.

\section{Estradiol upregulates the expression of endometrial sorcin}

Ovariectomized and delayed implantation mice models were used to examine whether sorcin expression is regulated by ovarian steroid hormones. In ovariectomized mice, sorcin expression was significantly induced by estrogen treatment, whereas progesterone alone had no effect. Combination of estrogen and progesterone also showed stimulatory effect on sorcin expression (Fig. 5A). Interestingly, similar results were found in delayed implantation model, and data indicated that progesterone 
NP

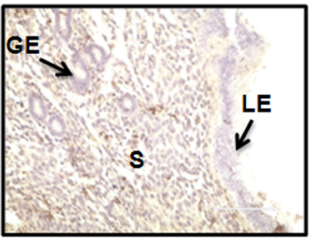

D4

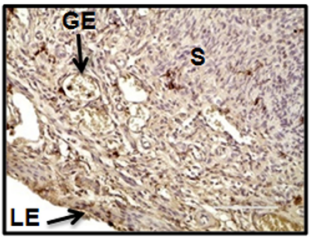

D6

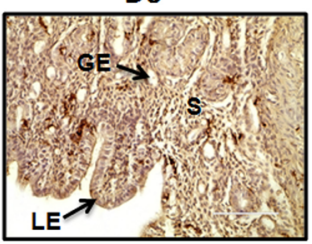

NC
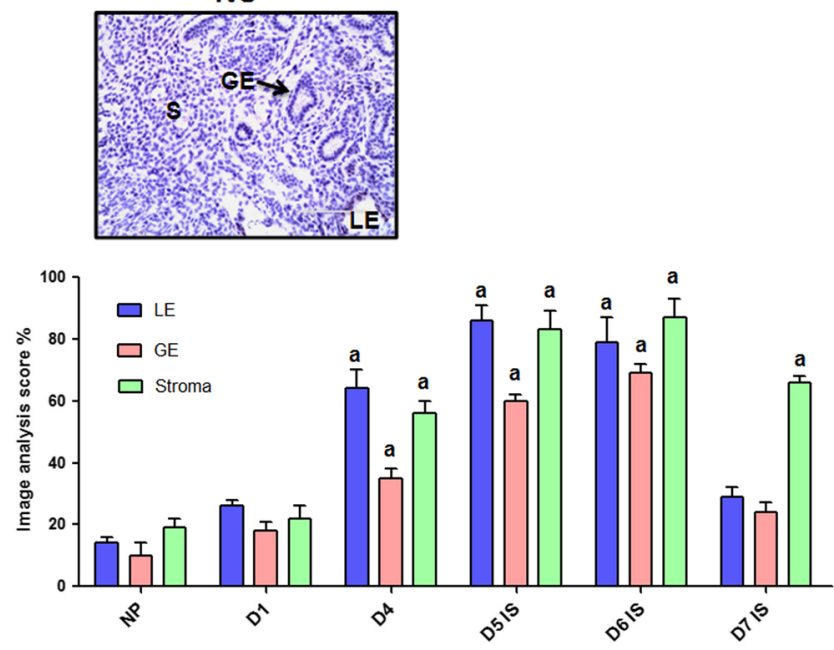

Figure 2

Immunohistochemistry of sorcin expression in mouse uteri during early pregnancy. Sorcin expression was measured in endometrium i.e. glandular epithelium (GE), luminal epithelium (LE), and stroma (S) at different days of pregnancy (D1, D4, D5, D6 and D7). Graph in lower panel shows image score analysis. IS, implantation site; NC, Negative control; NP, non-pregnant. $P$ values are ${ }^{2} P<0.001$ vs NP group. A full color version of this figure is available at https://doi.org/10.1530/JME-17-0153.

alone had no effect on sorcin, but with estrogen surge, the sorcin expression was significantly upregulated in mice uterus $(P<0.001)$ (Fig. 5B).

Immunohistochemical analysis suggested that expression of sorcin was high in LE, GE and stromal cells on the activation of implantation as compared to that in delayed implantation group (Fig. 5C).

Moreover, in in vitro experiment using primary culture of mouse EECs, the results of Western blot analysis and

\begin{tabular}{|lr}
\hline $\begin{array}{l}\text { http://jme.endocrinology-journals.org } \\
\text { https://doi.org/10.1530/JME-17-0153 }\end{array}$ & ○ 2018 Society for Endocrinology \\
Published by Bioscientifica Ltd. \\
Printed in Great Britain
\end{tabular}

A

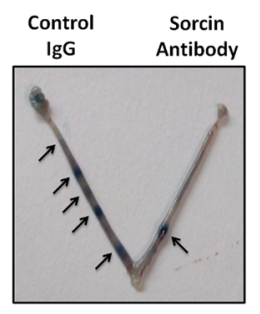

D5 p.c.

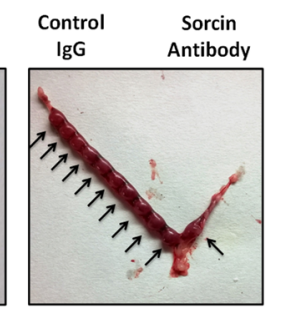

D10 p.c.

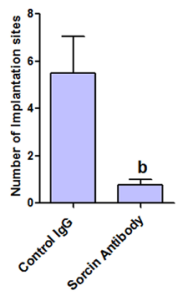

B
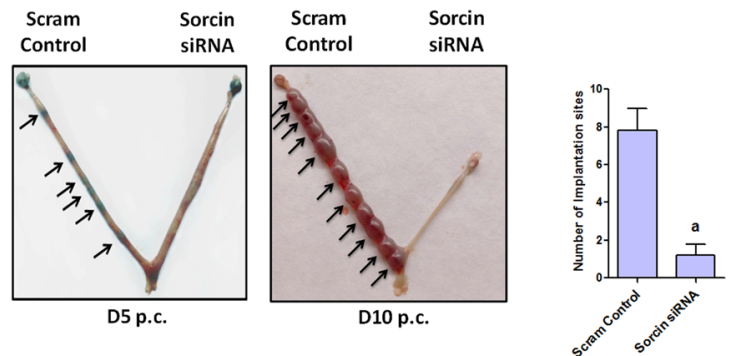

C
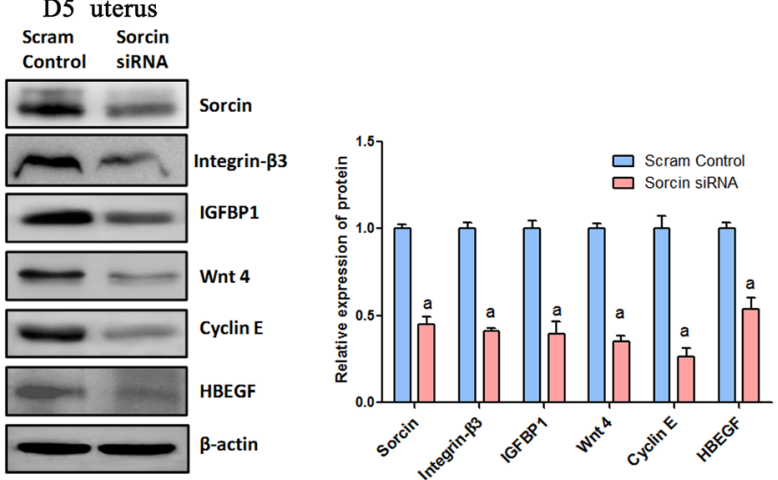

Figure 3

Effect of sorcin inhibition on the number of implantation sites. The right horn was injected with anti-sorcin or sorcin siRNA and the left horn was injected with control IgG/scrambled siRNA. ( $A$ and B) Representative images of uterus on D5 and D10 from the antibody- and siRNA-treated groups. (C) Left panel shows representative images of Western blotting for receptivity markers in scrambled control- and siRNA- treated uterine horn collected on D5 of pregnancy; Right panel shows densitometric quantitation of band intensity. $n=3$. $P$ values are ${ }^{a} P<0.001, b P<0.01$ vs control. A full color version of this figure is available at https://doi. org/10.1530/JME-17-0153.

immunocytochemistry showed that sorcin expression was induced in $\mathrm{E}_{2}$-treated EECs and also the combination of estrogen and progesterone showed a stimulatory effect on sorcin expression $(P<0.001)$ (Fig. $5 \mathrm{D}$ and $\mathrm{E})$. This in vitro experimental data further support our in vivo data as shown in Fig. 5A. These results clearly indicate that sorcin is regulated by estrogen in mouse endometrium.

\section{Sorcin silencing increased the intracellular calcium level in mouse EECs}

Since sorcin is a calcium-binding protein, it may affect the calcium homeostasis in endometrium during embryo 
A

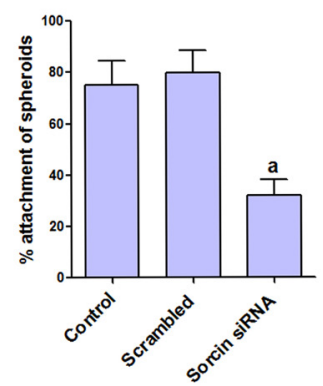

B
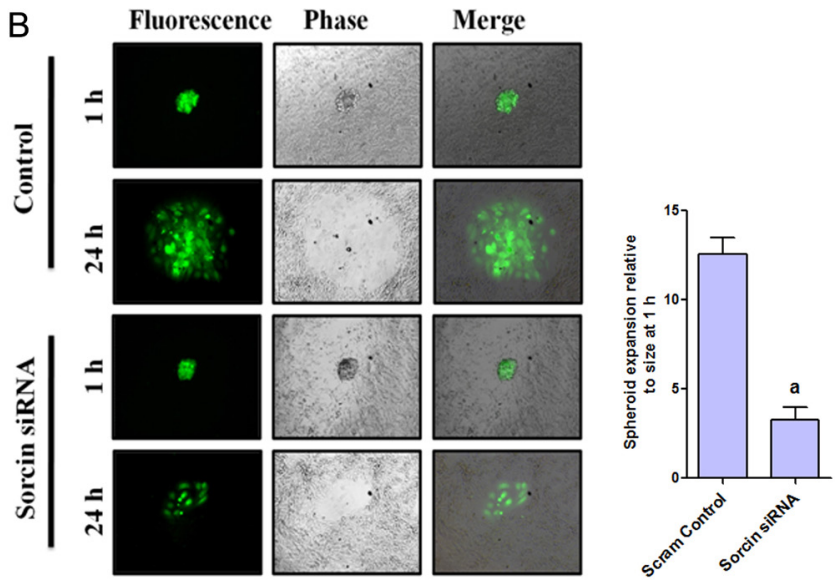

Figure 4

Attachment and expansion of BeWo trophoblast spheroids on RL95-2 cells. The RL95-2 monolayer grown in the 96-well plate were pretreated with sorcin siRNA for $6 \mathrm{~h}$ and allowed for $24 \mathrm{~h}$ of incubation, followed by the addition of spheroids stained with CMFDA cell tracker dye to each well and co-cultured for $1 \mathrm{~h}$. (A) Graph showing the percent attachment of spheroid on sorcin-silenced RL95-2 cells. (B) Representative images of BeWo spheroids outgrowth on RL95-2 monolayer. The spheroids were photographed at $1 \mathrm{~h}$ and $24 \mathrm{~h}$ after co-culture. Data are presented as spheroid expansion relative to their original size at $1 \mathrm{~h} . P$ values are a $P<0.001$ vs control. A full color version of this figure is available at https://doi.org/10.1530/JME-17-0153.

implantation thus our next aim was to measure the effect of sorcin on intracellular $\mathrm{Ca}^{+2}$ in EECs. For this, mouse primary EECs transfected with sorcin siRNA or scrambled siRNA and knockdown efficiency of sorcin siRNA was confirmed by Western blot analysis. A significant reduction in sorcin expression $(P<0.001)$ was observed $24 \mathrm{~h}$ after sorcin silencing (Supplementary Fig. 2B). The results of flow cytometric analysis revealed that silencing of sorcin in EECs significantly enhanced ( 2.2 fold) the influx of intracellular calcium in these cells as compared to that in scrambled siRNA-transfected EECs $(P<0.001)$ (Fig. 6A).

\section{Sorcin knock down significantly reduced the expression of VEGF, VEGFR-2 and its downstream signaling molecules}

Since angiogenesis is an important phenomenon during embryo implantation and is mediated mainly by VEGF
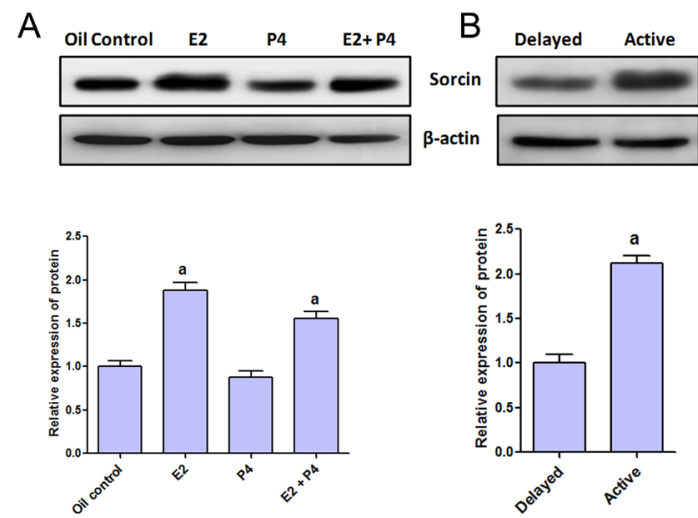

C
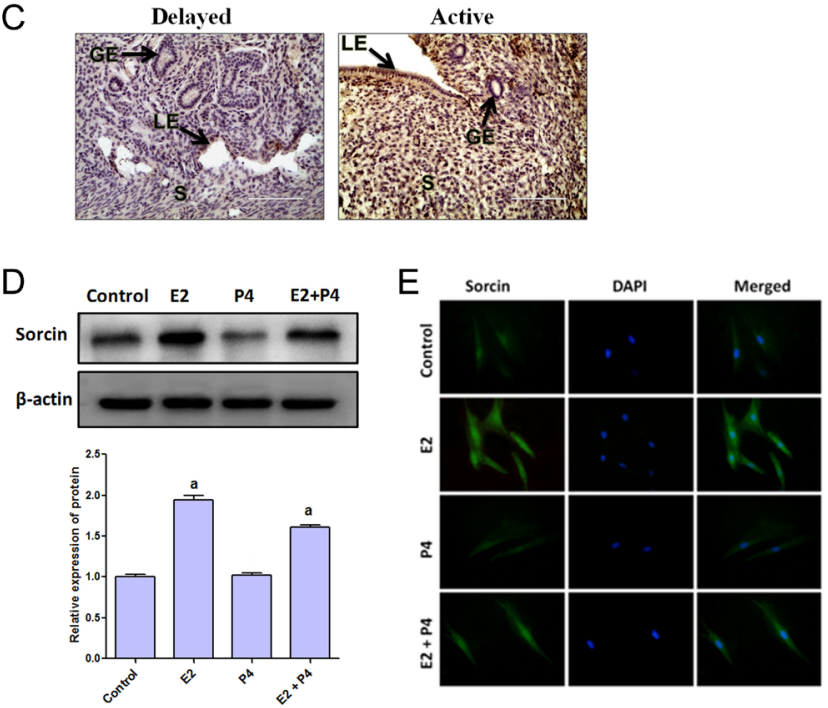

Figure 5

Role of ovarian hormones in regulation of sorcin expression.

(A) Ovariectomized mice treated with $\mathrm{E}_{2}(100 \mathrm{ng})$ or $\mathrm{P}_{4}(1 \mathrm{mg})$ were used to detect the expression pattern of sorcin in uterus. Representative Western blots for sorcin expression in vehicle- and hormone-treated groups have been shown. (B) For delayed implantation, pregnant mice were ovariectomized on $\mathrm{D} 3$. To maintain delay in implantation, $\mathrm{P}_{4}$ $(1 \mathrm{mg} / 30 \mathrm{~g}$ body weight) was given and to initiate implantation, estrogen surge $(25 \mathrm{ng} / 30 \mathrm{~g}$ body weight) was given to progesterone-primed delayed implantation mice on D7. The expression of sorcin in response delayed and after activation by $E_{2}$ surge was measured by Western blotting. (C) Immunohistochemical analysis of sorcin expression in LE, GE and stromal cells of uterine tissue in delayed and active groups. ( $D$ and $E$ ) Mouse primary EECs were treated with $E_{2}(10 n M), P_{4}(1 \mu M)$ and $E_{2}+P_{4}$ and Western blotting and immunocytochemistry was done to demonstrate the expression of sorcin protein. Representative images have been shown. Densitometry results are expressed as mean \pm S.E.M., $n=3$. $P$ values are a $P<0.001$ vs control. A full color version of this figure is available at https://doi.org/10.1530/JME-17-0153.

(Zhang et al. 2001, Wang \& Dey 2006, Demir et al. 2010, Bagheri et al. 2017), we measured the expression of VEGF and its associated downstream effector molecules like PI3K, AKT and NOS that are known to be involved in the process of angiogenesis. Quantification of VEGF level was analyzed in fresh conditioned media collected $24 \mathrm{~h}$ after 

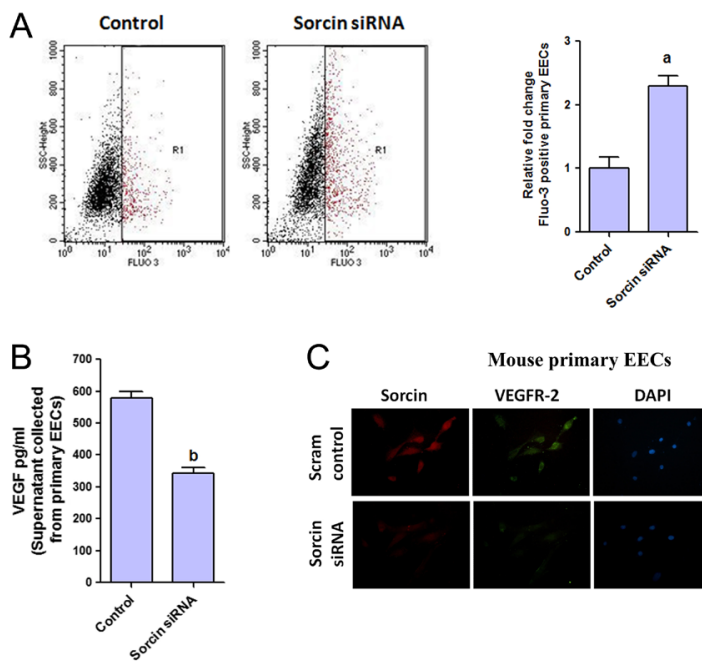

C
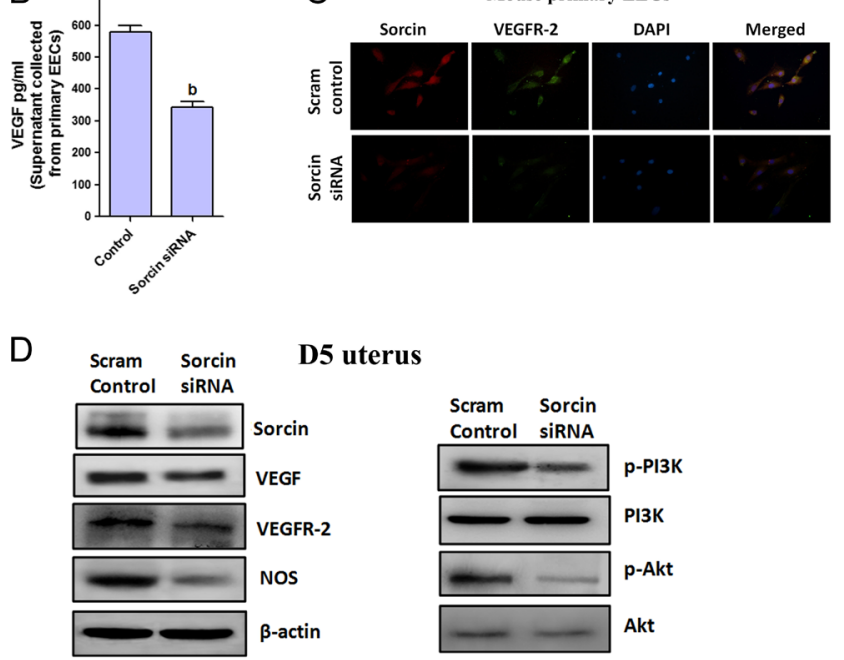

D5 uterus
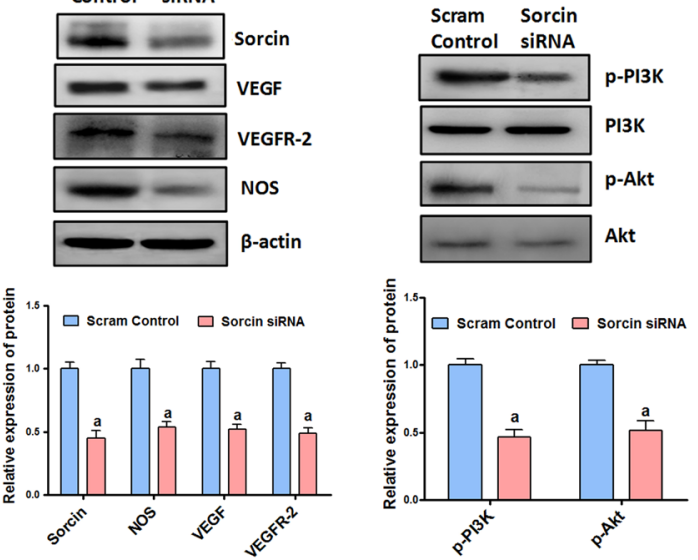

Figure 6

Effect of sorcin silencing on cytosolic free $\mathrm{Ca}^{+2}$, VEGF level, VEGFR-2 expression in mouse primary EECs in vitro and on signaling molecules (PI3K, Akt and NOS) in D5 uterus in vivo. (A) Fluorescence was measured from cells loaded with $2 \mu \mathrm{M}$ Fluo-3-AM dye. Exposure of cells to $10 \mu \mathrm{M}$ ionomycin induced a $\mathrm{Ca}^{+2}$ transient. (B) VEGF level in culture supernatants of mouse primary EECs measured by enzyme-linked immunosorbent assay. (C) Representative images of immunocytochemical analysis showing VEGFR-2 expression in EECs. (D) Representative images showing Western blot analysis of VEGF, VEGFR-2, PI3K, Akt and NOS in uterine horn collected on D5 pregnancy. Details have been given in 'material and methods' section. Results are expressed as mean \pm S.E.M., $P$ values are a $P<0.001$ and ${ }^{b} P<0.01$ vs scrambled control. A full color version of this figure is available at https://doi.org/10.1530/JME-17-0153.

sorcin siRNA transfection in mouse EECs. Interestingly, VEGF level was found to be low $(P<0.01)$ in conditioned media collected from transfected cells as compared to control group (Fig. 6B). Further, we performed immunocytochemical analysis of VEGFR-2 in mouse EECs transfected with sorcin siRNA. Our results showed reduced expression of VEGFR-2 in the mouse EECs (Fig. 6C).
A

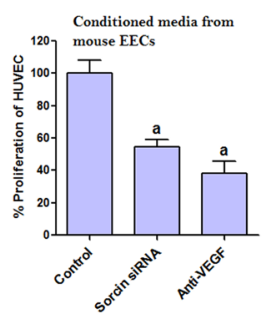

B
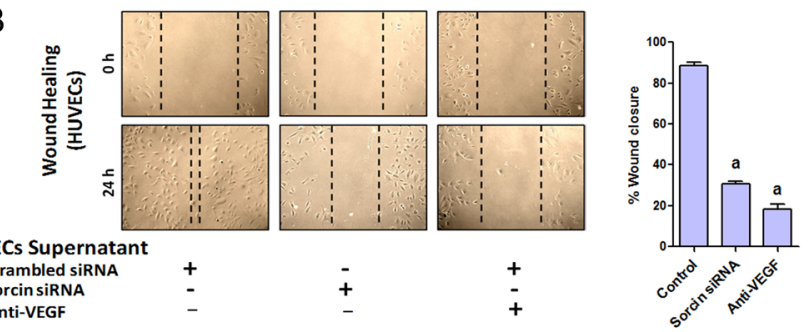

C

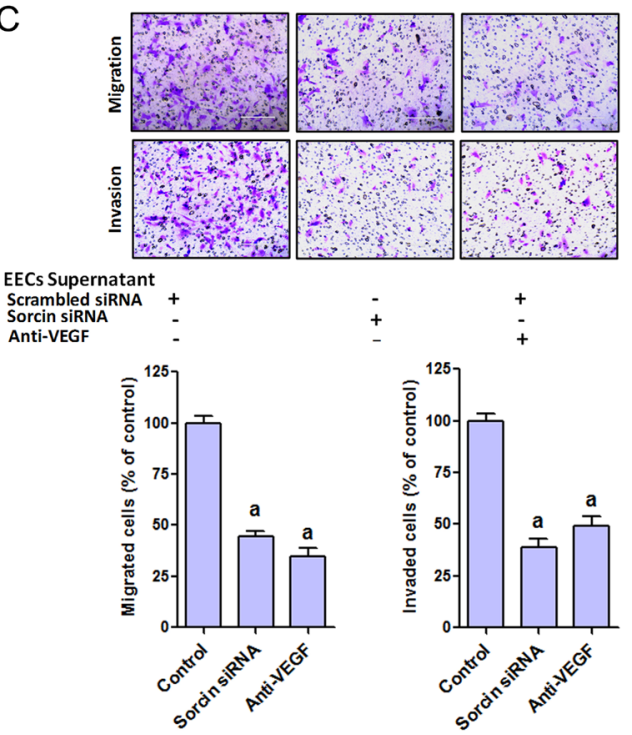

Figure 7

The proliferation, migration and invasion assay of HUVECs. (A) The proliferation of HUVECs was detected in various groups; HUVECs were cultured with supernatants $(20 \% \mathrm{~V} / \mathrm{V})$ from mouse primary EECs transfected with sorcin siRNA or scrambled siRNA. In additional group, a blocking anti-VEGF antibody was added in the supernatant from scrambled siRNA-treated EECs. Details have been given in 'materials and methods' section. (B) Analysis of migration of HUVECs was performed by scratch-wound healing assay. Representative images showing migration of HUVECs cultured for $24 \mathrm{~h}$ in the supernatant of control EECs and in the supernatant of EECs with sorcin blockade ( $\times 200$ magnification). Cell migration distance of the cells between the scratch edges was observed after $24 \mathrm{~h}$. (C) Transwell migration and matrigel invasion assays were done to analyse migration and invasion of HUVECs. The graph in the lower panel shows the relative percentage of migrated and invaded cells over control in three wells in each independent experiment (random fields were photographed and number of cells from three fields per well were counted). Results are expressed as mean \pm s.E.M., $n=3$. $P$ values are a $P<0.001$ vs scram control. A full color version of this figure is available at https://doi.org/10.1530/JME-17-0153. 


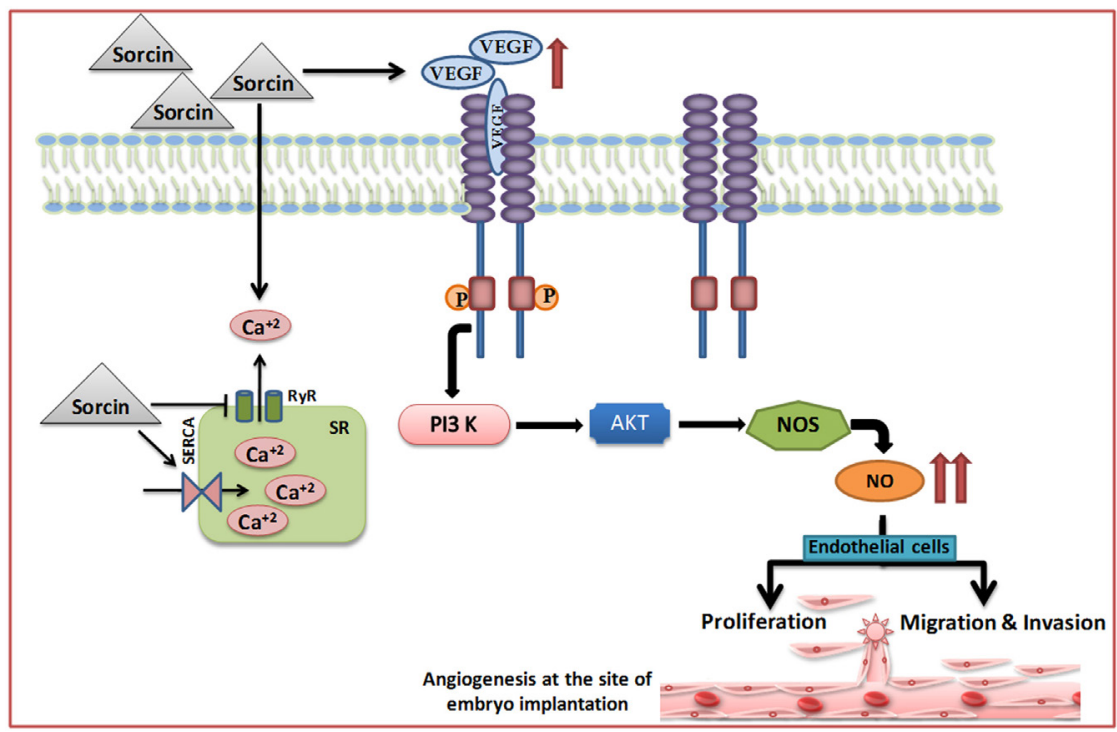

\section{Figure 8}

Schematic hypothetical representation of the molecular mechanism of sorcin in endometrium during embryo implantation. Sorcin maintains calcium homeostasis (Colotti et al. 2014) and induces angiogenic factor VEGF in endometrium and activates its downstream PI3K/Akt signaling cascade. Akt activates nitric oxide synthase (NOS) which in turn enhances the local nitric oxide (NO) level which regulates cellular proliferation, migration and invasion of endothelial cells and leads to the process of angiogenesis at implantation sites in the endometrium. A full color version of this figure is available at https:// doi.org/10.1530/JME-17-0153.
Further, the effect of in vivo silencing (on D3) of sorcin on expression of VEGF, VEGFR and downstream effectors was analyzed by Western blotting on D5 in pregnant mice. Results revealed a significant reduction in the expression of VEGF, VEGFR-2, PI3K, AKT and NOS $(P<0.001)$ in uterine horn transfected with sorcin siRNA (Fig. 6D). Above results indicated that sorcin mediates its angiogenic effect by regulating VEGF/PI3K/ Akt signaling.

\section{Sorcin blockade suppressed endothelial cell proliferation, migration and invasion}

Next, to analyze whether sorcin affects angiogenesis in endometrium, we performed experiments on HUVECs. HUVECs cultured in medium from sorcin-silenced EECs contained low VEGF concentration as compared to control group $(P<0.01)$ (Fig. 6B). To determine the angiogenic activity of the HUVECs, MTT assay, wound healing assay and matrigel migration/invasion assay were performed. The results revealed that $48 \mathrm{~h}$ after the addition of the culture medium from sorcin-silenced EECs, the proliferation, migration and invasion ability of HUVECs were significantly reduced $(P<0.001)$ as compared to that of control group (Fig. 7A, B and $\mathrm{C}$ ). When supernatant from control EECs was supplemented with anti-VEGF, similar results were observed with these parameters in HUVECs. Results indicate that the angiogenesis-inducing properties of sorcin (expressed in EEC) can be accounted for sorcin's VEGF-inducing ability.

\section{Discussion}

To the best of our knowledge, present study is the first report to investigate the expression, regulation and physiological function of sorcin in mouse uterus during the period of uterine receptivity and embryo implantation. The dynamics of sorcin protein expression showed low expression on D1, which was found to be increased on subsequent days and reached to maximum on D5 in mice. In mice, window of implantation lasts for less than $24 \mathrm{~h}$ i.e. initiates from D4 evening of the pregnancy thereafter uterus becomes non-receptive (refractory) to implantation by the afternoon of D5 (Wang \& Dey 2006). The findings indicated the possible role of sorcin during window of implantation in mice.

The spatio-temporal distribution study of sorcin in mouse uterus revealed that the expression of sorcin was significantly high in all compartments on D4 to D6. The expression was declined in LE and GE on D7, but was still detected high in stroma. The high expression of sorcin in the stromal cells on D7 indicated the possible involvement of sorcin in stromal cells-drivenevent 'decidualization', which begins just after embryo implantation (Abrahamsohn \& Zorn 1993, Wang \& Dey 2006, He et al. 2015) in mice. Thus, sorcin appears to play a critical role during endometrial receptivity and subsequently may also be involved in decidualization process as it continued to be expressed in stromal cells after implantation.

To analyze whether sorcin is important for embryo implantation, we knocked down the expression of 
sorcin. The intra-uterine injection of sorcin siRNA/sorcin antibody reduced the number of implantation sites in pregnant mice. Additionally, the downregulation of receptivity markers (Integrin $\beta 3$, HBEGF, IGFBP1, WNT4 and Cyclin E) in sorcin knocked down uterine horn confirmed the functional role of sorcin in endometrial receptivity. The result of in vitro attachment assay further provided the direct evidence that sorcin renders endometrium receptive both for attachment and invasion process. Herein, EECs monolayer transfected with sorcin siRNA showed remarkable reduction in attachment of BeWo spheroids on EECs. Moreover, significant inhibition in spheroids outgrowth attached to EECs was seen after $24 \mathrm{~h}$ of co-culture. These in vivo and in vitro data clearly indicate the critical involvement of sorcin in embryo implantation.

Ovarian steroids play an important role in uterine tissue remodeling and making the endometrium receptive for embryo implantation (Aplin \& Kimber 2004, Paulson 2011, Cha et al. 2012). Serum $\mathrm{E}_{2}$ and $\mathrm{P}_{4}$ levels vary throughout the estrous cycle (Wood et al. 2007). Therefore, it was interesting to analyse the $\mathrm{E}_{2^{-}}$and $\mathrm{P}_{4}$-mediated regulation of sorcin expression in endometrium. In delayed implantation experiment, the sorcin expression was significantly increased when embryos were implanted on giving $\mathrm{E}_{2}$ surge to terminate the delay in pregnancy on D7. Also, $\mathrm{E}_{2}$ significantly promoted the expression of sorcin in the uterus of ovariectomized mouse. These results were consistent with the observation expression pattern of sorcin during estrous cycle, which was increased during estrogen-dominant estrus phase and declined during progesterone-dominating diestrus phase. The in vitro experiment on mouse EECs also showed that estrogen alone or in combination with progesterone enhanced the expression of sorcin in these cells. Collectively, evidences suggest that expression of sorcin is regulated by estrogen in uterus during estrous cycle and also during early pregnancy.

Calcium homeostasis is a necessary phenomenon during embryo implantation and the maintenance of calcium level is important at embryo-uterine interface (Yoshinaga 2008). Several calcium-binding proteins such as CaBP-9k, CaBP-28k and $\mathrm{S} 100$ protein family members have been reported to play a role in the maintenance of endometrial receptivity (Luu et al. 2004, Tong et al. 2010, Liu et al. 2012). The roles established for calcium-binding proteins emphasize their ability to enhance $\mathrm{Ca}^{+2}$ transport and increase the capacity of cells to store $\mathrm{Ca}^{+2}$ (Luu et al. 2004). Sorcin increases calcium accumulation in the endoplasmic reticulum and decreases cytoplasmic $\mathrm{Ca}^{+2}$ and maintains calcium level in fibroblasts cells (Lalioti et al. 2014). However, the role of sorcin-mediated calcium homeostasis during embryo implantation is not yet well known. In our study, mouse EECs after sorcin knock down, showed increase in cytoplasmic $\mathrm{Ca}^{+2}$ level. Sarco/ endoplasmic reticulum $\mathrm{Ca}^{+2}$ ATPase (SERCA) activation is reported to be involved in the induction of angiogenesis by promoting proliferation and migration of vascular smooth muscle cells (Shukla et al. 1997, Birkett et al. 1999). Sorcin activates SERCA, which further increases calcium accumulation in endoplasmic reticulum (ER) (Lalioti et al. 2014), whereas thapsigargin (SERCA inhibitor) inhibits angiogenesis via depletion of intracellular calcium pools in human umbilical vein endothelial cells (HUVECs) (Shukla et al. 2001). The depletion of sorcin is also known to decrease VEGF expression and cause inhibition of epithelial-to-mesenchymal transition as studied in breast cancer cells (Hu et al. 2014). Angiogenesis is an important phenomenon during embryo implantation and is mediated mainly by VEGF (Zhang et al. 2001, Wang \& Dey 2006, Demir et al. 2010). Thus, we checked whether sorcin was involved in calcium-mediated angiogenesis in the uterus for successful establishment of pregnancy in mice. Interestingly, we found a significant decline in the expression of both VEGF and its receptor VEGFR-2 in the uterine horn receiving sorcin siRNA. The reduction in VEGF level was also found in conditioned media collected from sorcin siRNA-transfected EECs. Since the phenomenon of angiogenesis involves the proliferation and migration of endothelial cells, the effect of sorcin silencing on angiogenesis was checked on human umbilical vein endothelial cells (HUVECs) (Shukla et al. 2001, Print et al. 2004). The HUVECs cultured in media collected from sorcin-depleted EECs, showed a reduction in the proliferation, migration and invasion thereof. Similarly, administration of anti-VEGF antibody reversed the effect of sorcin on HUVECs. These results clearly indicate that sorcin regulates angiogenesis in the endometrium via regulating VEGF pathway, during embryo implantation.

VEGF mediates its action via VEGFR and activates PI-3-kinase/Akt-dependent activation of nitric oxide synthase (NOS), which plays an important role during embryo implantation (Morales-Ruiz et al. 2000, Ma et al. 2003, Koch et al. 2011). The higher NOS expression was detected in peri-implantation uterus of mice leading to higher nitric oxide (NO) production, which is required for successful embryo implantation (Novaro et al. 1997, Saxena et al. 2000). NO is known to act as a local vasodilator and an angiogenic mediator in murine 
endometrium (Novaro et al. 1997, Saxena et al. 2000). In our study, the sorcin silencing inhibited the activation of PI3-K and Akt, which led to suppression of activation of downstream NOS required for NO production in uterus. The suppressed production of NO might adversely affect the angiogenesis at the implantation sites, which can lead to the implantation failure (Saxena et al. 2000). Thus, our studies revealed that sorcin is essential for maintaining the activation of VEGF-mediated signaling and production of $\mathrm{NO}$ in endometrium required for successful implantation in mice.

\section{Conclusion}

Taken together, the current study demonstrated that sorcin may have functional significance in the initiation and maintenance of the window of receptivity and subsequent embryo implantation. Attenuation of sorcin expression led to embryo implantation failure in both in vivo and in vitro settings. Sorcin is tightly regulated by $\mathrm{E}_{2}$ during window of implantation and exerts its effect via VEGF/PI3-K/Akt pathway and facilitates angiogenesis at the site of embryo implantation (Fig. 8). Further, the altered regulation of sorcin might cause imbalance in $\mathrm{Ca}^{+2}$ homeostasis and might result in inadequate functioning of endometrium leading to recurrent implantation failure. However, the role of sorcin in developing embryos needs to be explored further, which might delineate the absolute cause of pregnancy failure due to suppressed expression of sorcin. This study explored the molecular function of sorcin in establishment of pregnancy, thus provides a significant addition towards understanding the implantation biology and infertility. Future studies on clinical validation of sorcin in infertile patients are likely to open the opportunities for the development of novel strategies for infertility management.

\section{Supplementary data}

This is linked to the online version of the paper at https://doi.org/10.1530/ JME-17-0153.

\section{Declaration of interest}

The authors declare that there is no conflict of interest that could be perceived as prejudicing the impartiality of the research reported.

\section{Funding}

Financial support from CSIR is gratefully acknowledged.

\section{Acknowledgement}

The authors wish to thank A L Vishwakarma, Sophisticated Analytical Instrument Facility, CSIR-Central Drug Research Institute, for help in flow cytometric analysis. This is CDRI manuscript number 231/2017/AD.

\section{References}

Abrahamsohn PA \& Zorn TM 1993 Implantation and decidualization in rodents. Journal of Experimental Zoology 266 603-628. (https://doi. org/10.1002/jez.1402660610)

Aplin JD \& Kimber SJ 2004 Trophoblast-uterine interactions at implantation. Reproductive Biology and Endocrinology 248 (https://doi.org/10.1186/1477-7827-2-48)

Bagheri A, Chianeh YR, Kumar P \& Rao P 2017 Angiogenic factors in relation to embryo implantation. International Journal of Reproduction, Contraception, Obstetrics and Gynecology 3 872-879. (https://doi. org/10.5455/2320-1770.ijrcog20141201)

Birkett SD, Jeremy JY, Watts SM, Shukla N, Angelini GD \& McArdle CA 1999 Inhibition of intracellular Ca2+ mobilisation by low antiproliferative concentrations of thapsigargin in human vascular smooth-muscle cells. Journal of Cardiovascular Pharmacology and Therapeutics 33 204-211. (https://doi.org/10.1097/00005344199902000-00005)

Byers SL, Wiles MV, Dunn SL \& Taft RA 2012 Mouse estrous cycle identification tool and images. PLOS ONE 7 e35538. (https://doi. org/10.1371/journal.pone.0035538)

Cha J, Sun X \& Dey SK 2012 Mechanisms of implantation: strategies for successful pregnancy. Nature Medicine 18 1754-1767. (https://doi. org/10.1038/nm.3012)

Chen JI, Hannan NJ, Mak Y, Nicholls PK, Zhang J, Rainczuk A, Stanton PG, Robertson DM, Salamonsen LA \& Stephens AN 2009 Proteomic characterization of midproliferative and midsecretory human endometrium. Journal of Proteome Research 8 2032-2044. (https://doi.org/10.1021/pr801024g)

Colotti G, Poser E, Fiorillo A, Genovese I, Chiarini V \& Ilari A 2014 Sorcin, a calcium binding protein involved in the multidrug resistance mechanisms in cancer cells. Molecules 19 13976-13989. (https://doi.org/10.3390/molecules190913976)

Demir R, Yaba A \& Huppertz B 2010 Vasculogenesis and angiogenesis in the endometrium during menstrual cycle and implantation. Acta Histochemica 112 203-214. (https://doi.org/10.1016/j. acthis.2009.04.004)

Guo B, Tian XC, Li DD, Yang ZQ, Cao H, Zhang QL, Liu JX \& Yue ZP 2014 Expression, regulation and function of Egr1 during implantation and decidualization in mice. Cell Cycle 13 2626-2640. (https://doi.org/10.4161/15384101.2014.943581)

Hannan NJ, Paiva P, Meehan KL, Rombauts LJ, Gardner DK \& Salamonsen LA 2011 Analysis of fertility-related soluble mediators in human uterine fluid identifies VEGF as a key regulator of embryo implantation. Endocrinology 152 4948-4956. (https://doi. org/10.1210/en.2011-1248)

He H, Kong S, Liu F, Zhang S, Jiang Y, Liao Y, Jiang Y, Li Q, Wang B, Zhou Z \& Wang H 2015 Rbbp7 is required for uterine stromal decidualization in mice. Biology of Reproduction 93 13. (https://doi. org/10.1095/biolreprod.115.129015)

Herve MA, Meduri G, Petit FG, Domet TS, Lazennec G, Mourah S \& Perrot-Applanat M 2006 Regulation of the vascular endothelial growth factor (VEGF) receptor Flk-1/KDR by estradiol through VEGF in uterus. Journal of Endocrinology 188 91-99. (https://doi. org/10.1677/joe.1.06184)

Ho H, Singh H, Aljofan M \& Nie G 2012 A high-throughput in vitro model of human embryo attachment. Fertility and Sterility $\mathbf{9 7}$ 974-978. (https://doi.org/10.1016/j.fertnstert.2012.01.116) 
Hu Y, Li S, Yang M, Yan C, Fan D, Zhou Y, Zhang Y, Yague E \& Xiong D 2014 Sorcin silencing inhibits epithelial-to-mesenchymal transition and suppresses breast cancer metastasis in vivo. Breast Cancer Research and Treatment 143 287-299. (https://doi.org/10.1007/ s10549-013-2809-2)

Huang Y, Cai LW \& Yang R 2012 Expression of maspin in the early pregnant mouse endometrium and its role during embryonic implantation. Comparative Medicine 62 179-184.

Koch S, Tugues S, Li X, Gualandi L \& Claesson-Welsh L 2011 Signal transduction by vascular endothelial growth factor receptors. Biochemical Journal 437 169-183. (https://doi.org/10.1042/BJ20110301)

Kodaman PH \& Taylor HS 2004 Hormonal regulation of implantation. Obstetrics and Gynecology Clinics of North America 31 745-766. (https:/doi.org/10.1016/j.ogc.2004.08.008)

Lalioti VS, Ilari A, O'Connell DJ, Poser E, Sandoval IV \& Colotti G 2014 Sorcin links calcium signaling to vesicle trafficking, regulates Pololike kinase 1 and is necessary for mitosis. PLOS ONE 9 e85438. (https://doi.org/10.1371/journal.pone.0085438)

Lessey BA, Damjanovich L, Coutifaris C, Castelbaum A, Albelda SM \& Buck CA 1992 Integrin adhesion molecules in the human endometrium. Correlation with the normal and abnormal menstrual cycle. Journal of Clinical Investigation 90 188-195. (https://doi. org/10.1172/JCI115835)

Liang XH, Zhao ZA, Deng WB, Tian Z, Lei W, Xu X, Zhang XH, Su RW \& Yang ZM 2010 Estrogen regulates amiloride-binding protein 1 through CCAAT/enhancer-binding protein-beta in mouse uterus during embryo implantation and decidualization. Endocrinology 151 5007-5016. (https://doi.org/10.1210/en.2010-0170)

Liu XM, Ding GL, Jiang Y, Pan HJ, Zhang D, Wang TT, Zhang RJ, Shu J, Sheng JZ \& Huang HF 2012 Down-regulation of S100A11, a calciumbinding protein, in human endometrium may cause reproductive failure. Journal of Clinical Endocrinology and Metabolism 97 3672-3683. (https://doi.org/10.1210/jc.2012-2075)

Long X, Zhang M, Chen X, He J, Ding Y, Zhang C, Liu X \& Wang Y 2015 Expression of KRAS in the endometrium of early pregnant mice and its effect during embryo implantation. Reproductive BioMedicine Online 31 51-61. (https://doi.org/10.1016/j.rbmo.2015.04.005)

Luu KC, Nie GY \& Salamonsen LA 2004 Endometrial calbindins are critical for embryo implantation: evidence from in vivo use of morpholino antisense oligonucleotides. PNAS $1018028-8033$. (https://doi.org/10.1073/pnas.0401069101)

Ma WG, Song H, Das SK, Paria BC \& Dey SK 2003 Estrogen is a critical determinant that specifies the duration of the window of uterine receptivity for implantation. PNAS 100 2963-2968. (https://doi. org/10.1073/pnas.0530162100)

Manohar M, Khan H, Sirohi VK, Das V, Agarwal A, Pandey A, Siddiqui WA \& Dwivedi A 2014 Alteration in endometrial proteins during early- and mid-secretory phases of the cycle in women with unexplained infertility. PLOS ONE 9 e111687. (https://doi. org/10.1371/journal.pone.0111687)

Matsumoto T, Hisamatsu Y, Ohkusa T, Inoue N, Sato T, Suzuki S, Ikeda Y \& Matsuzaki M 2005 Sorcin interacts with sarcoplasmic reticulum $\mathrm{Ca}(2+)$-ATPase and modulates excitation-contraction coupling in the heart. Basic Research in Cardiology 100 250-262. (https://doi. org/10.1007/s00395-005-0518-7)

Morales-Ruiz M, Fulton D, Sowa G, Languino LR, Fujio Y, Walsh K \& Sessa WC 2000 Vascular endothelial growth factor-stimulated actin reorganization and migration of endothelial cells is regulated via the serine/threonine kinase Akt. Circulation Research 86 892-896. (https://doi.org/10.1161/01.RES.86.8.892)

Nie GY, Li Y, Wang J, Minoura H, Findlay JK \& Salamonsen LA 2000 Complex regulation of calcium-binding protein D9k (calbindin$\mathrm{D}(9 \mathrm{k}))$ in the mouse uterus during early pregnancy and at the site of embryo implantation. Biology of Reproduction 62 27-36. (https://doi. org/10.1095/biolreprod62.1.27)
Novaro V, González E, Jawerbaum A, Rettori V, Canteros G \& Gimeno MF 1997 Nitric oxide synthase regulation during embryonic implantation. Reproduction, Fertility and Development 9 557-564. (https://doi.org/10.1071/R97005)

Paulson RJ 2011 Hormonal induction of endometrial receptivity. Fertility and Sterility 96 530-535. (https://doi.org/10.1016/j. fertnstert.2011.07.1097)

Print C, Valtola R, Evans A, Lessan K, Malik S \& Smith S 2004 Soluble factors from human endometrium promote angiogenesis and regulate the endothelial cell transcriptome. Human Reproduction 19 2356-2366. (https://doi.org/10.1093/humrep/deh411)

Saxena D, Purohit SB, Kumer GP \& Laloraya M 2000 Increased appearance of inducible nitric oxide synthase in the uterus and embryo at implantation. Nitric Oxide 4 384-391. (https://doi. org/10.1006/niox.2000.0286)

Shukla N, Jeremy JY, Nicholl P, Krijgsman B, Stansby G \& Hamilton G 1997 Short-term exposure to low concentrations of thapsigargin inhibits replication of cultured human vascular smooth muscle cells. British Journal of Surgery $\mathbf{8 4} 325-330$. (https://doi.org/10.1002/ bjs.1800840315)

Shukla N, Freeman N, Gadsdon P, Angelini GD \& Jeremy JY 2001 Thapsigargin inhibits angiogenesis in the rat isolated aorta: studies on the role of intracellular calcium pools. Cardiovascular Research 49 681-689. (https://doi.org/10.1016/S0008-6363(00)00269-8)

Singh H, Nardo L, Kimber SJ \& Aplin JD 2010 Early stages of implantation as revealed by an in vitro model. Reproduction 139 905-914. (https://doi.org/10.1530/REP-09-0271)

Sirohi VK, Popli P, Sankhwar P, Kaushal JB, Gupta K, Manohar M \& Dwivedi A 2017 Curcumin exhibits anti-tumor effect and attenuates cellular migration via Slit-2 mediated down-regulation of SDF-1 and CXCR4 in endometrial adenocarcinoma cells. Journal of Nutritional Biochemistry 44 60-70. (https://doi.org/10.1016/j. jnutbio.2016.12.021)

Sugino N, Kashida S, Karube-Harada A, Takiguchi S \& Kato H 2002 Expression of vascular endothelial growth factor (VEGF) and its receptors in human endometrium throughout the menstrual cycle and in early pregnancy. Reproduction 123 379-387. (https://doi. org/10.1530/rep.0.1230379)

Tong XM, Lin XN, Song T, Liu L \& Zhang SY 2010 Calcium-binding protein S100P is highly expressed during the implantation window in human endometrium. Fertility and Sterility 94 1510-1518. (https://doi.org/10.1016/j.fertnstert.2009.07.1667)

Van der Bliek AM, Meyers MB, Biedler JL, Hes E \& Borst P 1986 A 22-kd protein (sorcin/V19) encoded by an amplified gene in multidrugresistant cells, is homologous to the calcium-binding light chain of calpain. EMBO Journal 5 3201-3208.

Walter LM, Rogers PA \& Girling JE 2010 Differential expression of vascular endothelial growth factor-A isoforms in the mouse uterus during early pregnancy. Reproductive Biomedicine Online 21 803-811. (https://doi.org/10.1016/j.rbmo.2010.07.005)

Wang H \& Dey SK 2006 Roadmap to embryo implantation: clues from mouse models. Nature Reviews Genetics 7 185-199. (https://doi. org/10.1038/nrg1808)

Wood GA, Fata JE, Watson KL \& Khokha R 2007 Circulating hormones and estrous stage predict cellular and stromal remodeling in murine uterus. Reproduction 133 1035-1044. (https://doi.org/10.1530/REP-060302)

Xie X, Dwyer MD, Swenson L, Parker MH \& Botfield MC 2001 Crystal structure of calcium-free human sorcin: a member of the penta-EFhand protein family. Protein Science 10 2419-2425. (https://doi. org/10.1110/ps.ps.36701)

Yoshinaga K 2008 Review of factors essential for blastocyst implantation for their modulating effects on the maternal immune system. Seminars in Cell and Developmental Biology 19 161-169. (https://doi. org/10.1016/j.semcdb.2007.10.006) 
Zhang J, Wang L, Cai L, Cao Y \& Duan E 2001 The expression and function of VEGF at embryo implantation "window" in the mouse. Chinese Science Bulletin 46 409-411. (https://doi.org/10.1007/BF03183277)

Zhang S, Ong CN \& Shen HM 2004 Critical roles of intracellular thiols and calcium in parthenolide-induced apoptosis in human colorectal cancer cells. Cancer Letters 208 143-153. (https://doi.org/10.1016/j. canlet.2003.11.028)

Zhang RJ, Zou LB, Zhang D, Tan YJ, Wang TT, Liu AX, Qu F, Meng Y, Ding GL, Lu YC \& Lv PP 2012 Functional expression of large- conductance calcium-activated potassium channels in human endometrium: a novel mechanism involved in endometrial receptivity and embryo implantation. Journal of Clinical Endocrinology and Metabolism 97 543-553. (https://doi.org/10.1210/ jc.2011-2108)

Zhang S, Lin H, Kong S, Wang S, Wang H, Wang H \& Armant DR 2013 Physiological and molecular determinants of embryo implantation. Molecular Aspects of Medicine 34 939-980. (https://doi.org/10.1016/j. mam.2012.12.011

Received in final form 24 November 2017

Accepted 20 December 2017

Accepted Preprint published online 22 December 2017 http://jme.endocrinology-journals.org https://doi.org/10.1530/JME-17-0153 (c) 2018 Society for Endocrinology Published by Bioscientifica Ltd. Printed in Great Britain 